Another line of research consisted in preparing a number of derivatives of phenoxyacethydroxamic acid and determining their fungistatic activity against Fusarium culmorum, Alternario solani and Rhizoctonia solani ${ }^{6}$. Chlor-derivatives of phenoxyacethydroxamic acid proved to exert a particularly strong fungistatic activity in vitro.

Thus 4 - chloro - 2 - methylphenoxyacethydroxamic acid was effective against $F$. culmorum at a concentration 0.005 per cent in solid agar culture medium. 2,4-Dichlorophenoxyacethydroxamic acid was effective against all three fungi examined at concentration 0.025 per cent. Similar activity was shown by 3,4-, 2,5-di-and 2,4,6-trichloro-derivatives.

The same group of compounds was examined against pathogenic fungi. 3,4-Dichlorophenoxyacethydroxamic acid was found to be particularly effective not only against Trichophyton but also against various pathogenic yeasts. It completely inhibited growth of Candida albicans, C. krusei, $C$. tropicalis, Cryptococcus neoformans, Geotrichum 1 and Geotrichum malatensis 53 when used in concentration $0.003-0.025$ per cent in liquid Sabouraud medium.

J. ALKIFWICZ

Z. ECKSTEIN

H. HALWEG

P. KrakówKa

T. URBAŃSKI

Department of Dermatology,

Municipal Hospital No. 1, Poznan.

Department of Chemistry,

Institute of Technology,

Warsaw.

Laboratory of Mycology,

Institute of Tuberculosis, Warsaw.

${ }^{1}$ Halweg, H., and Krakowka, P., Bull. Acad. Pol. Sci., Cl. 3, 3, 437 (1955) ; Gruzlica (Tuberculosis), 24, 233 (1956)

Urbański, T., Malinowski, S., Piotrowska, H., and Zakrzewski, L., Roczniki Chem., 27, 47 (1953).

"Urbański, T., Hornung, S., Slopek, S., and Venulet, J., Nature, 170, 753 (1952).

* Hornung, S., et al., Gruzlica (Tuberculosis), 24, 335 (1956) ; 25. Pol. Sci. C1. 3, 3, 487 (1955): and Manowska, W., Bull. Acad. (1955).

Venulet, J., and Jakimowska, K., Gruzlica (Tuberculosis), 21, 731 (1953). Urbański, T., Nature, 168, 267 (1950).

- Eckstein, Z., and Urbański, T., Przemysl. Chem. (Chem. Industry), 12, 640 (1956); Bull. Acad. Pol. Sci., Cl. 3, 4, 627 (1956).

\section{Ethyl-3-Indoleacetate : an Artefact in Extracts of Immature Corn Kernels}

THE isolation and identification of 3 -indoleacetic acid in corn kernels has been well established ${ }^{2}$. While characterization of ethyl-3-indoleacetate in ethanol extracts of corn kernels, Zea mays, variety Golden Cross, has been reported from this laboratory ${ }^{2}$, it has been suggested that ethanol extraction may have resulted in the formation of an artefact ${ }^{3}$.

To avoid esterification, peroxide-free ethyl ether was used as the extractant in the present study. Freshly harvested, immature (early milk stage) corn kernels, variety Golden Cross, were covered with ethyl ether and extracted for two hours at $2^{\circ} \mathrm{C}$. ('free auxin' or first fraction). Additional cold ethyl other washings of the kernels were added to the original extract. The kernels were again covered with ethyl ether and extracted for $48 \mathrm{hr}$. at $25^{\circ} \mathrm{C}$. ('bound auxin' or second fraction). The first and second ethyl other fractions were further separated into acidic and non-acidic ('neutral') portions by extraction with 5 per cent aqueous sodium bicarbonate. The bicarbonate solution containing the acidic sub. stances was adjusted to $p \mathrm{H} 2.8$ with hydrochloric acid and extracted with ethyl ether. The aqueous layer was discarded, and the acidic substances in the ether layer were retained. Acidic and non-acidic ethereal solutions were separately concentrated under reduced pressure with the bath temperature kept below $25^{\circ} \mathrm{C}$. The constituents of the concentrated extracts were partitioned by paper chromatographic techniques (Whatman No. 1 filter paper, solvent mixture 2-PrOH : $\left.\mathrm{NH}_{3}: \mathrm{H}_{2} \mathrm{O} \quad(8: 1: 1 \quad \mathrm{v} / \mathrm{v})^{4}\right)$ and their biological activities assayed ${ }^{5}$.

3-Indoleacetic acid was detected in the chromatographically separated acid fractions through biological assays, by development of characteristic colours with Salkowski and Ehrlich spray reagents, and ultra-violet absorption spectra. In addition, growth-promoting zones with $R_{F} \quad 0 \cdot 25-0 \cdot 33$ and growth-inhibiting zones with $R_{F} 0 \cdot 60-0 \cdot 70$ were noted in both acid fractions. A similar observation of growth-stimulating and -inhibiting zones has been reported for absolute ethanol extracts of corn kernels (ref. 1, Kefford).

Growth-stimulating zones of $R_{F}, 0 \cdot 80-0.90$ were observed in histograms of neutral fractions. The $R_{F}$ values were similar to those reported for ethyl-3indoleacetate and 3-indoleacetonitrile; however, the presence of an indole moiety could not be established by ultra-violet absorption spectra or by the reactions to Salkowski and Ehrlich colour reagents. Absence of ethyl-3-indole-acetate in the ethyl ether extracts of corn kernels, $Z e a$ mays, variety Golden Cross, indicated that it was previously isolated as an artefact? The characterization of this neutral growth substance is now in progress, and a more detailed report will be published elsewhere.

We are indebted to Dr. F. G. Teubner for his interest and suggestions throughout this investigation.

This work was supported in part by the National Science Foundation, Washington, D.C.

HeNRy N. Fukui

JoAnne E. DeVries

S. H. WITTWER

H. M. SELI

Departments of Agricultural Chemistry and Horticulture,

Michigan State University,

East Lansing. June 17.

'Haagen-Smit, A. J., Dandliker, W. B., Wittwer, S. H., and Murneek, A. E., Amer. J. Bot., 33, 118 (1946). Berger, J., and Avery, jun., (1955). vilitos, A. J., and Meudt, W., Contrib. Boyce Thompson Inst., 17, 197 (1953). Yamaki, T., and Nakamura, K., Sci. Papers Coll. 'Gen. Educ., Univ. of Tokyo, 2, 81 (1952).

${ }^{2}$ Redemann, C. T., Wittwer, S. H., and Sell, H. M., Arch. Biochem. and Biophys., 32, 80 (1951).

${ }^{3}$ Henbest, H. B., Jones, E. R. H., and Smith, G. F., J. Chem. Soc., 3796 (1953). - Stowe, B. B., and Thimann, K. V., Arch. Biochem. and Biophys.,

5 Nitsch, J. P., and Nitsch, C., Plant Physiol., 31, 94 (1954).

\section{Actinomycete Disintegration of Raw Wool}

DURING the course of investigations on bacterial disintegration of raw wool, the presence of Actinomycetes in rotted wool was often noted. These organisms, however, rarely appeared in culture, perhaps because of the prevalence of Pseudomonas aeruginosa the antagonistic effects of which are well known. Eventually Actinomycetes were isolated 